\title{
Evaluation of notch effects in low cycle fatigue of alloy 718 using critical distances
}

\author{
Robert Eriksson ${ }^{1, *}$, Kjell Simonsson ${ }^{1}$, Daniel Leidermark ${ }^{1}$, and Johan Moverare ${ }^{2}$ \\ ${ }^{1}$ Division of Solid Mechanics, Department of Management and Engineering, Linköping University, 58183 Linköping, Sweden \\ ${ }^{2}$ Division of Engineering Materials, Department of Management and Engineering, Linköping University, 58183 Linköping, Sweden
}

\begin{abstract}
Gas turbine disks contain many notch-like features acting as stress raisers. The fatigue life based on the notch root stress may be overly conservative as the steep stress gradient in front of the notch may give rise to so-called notch support. In the current work, the theory of critical distances was applied to the prediction of the total fatigue life of low cycle fatigued, notched specimens made from alloy 718 . The fatigue tests were performed at $450{ }^{\circ} \mathrm{C}$ and $550{ }^{\circ} \mathrm{C}$. It was found that, for lives shorter than $5000-10000$ cycles, the notched specimens had longer lives than would have been expected based on the notch root strain. For lives longer than 5000-10000 cycles, there were no notch support. The life prediction for notched specimens could be significantly improved by basing the prediction on the strain chosen some distance from the notch (the critical distance). An expression for calculating the critical distance based on the notch root strain was suggested.
\end{abstract}

\section{Introduction}

Materials used for gas turbine disks should have properties such as high yield and tensile strength, reasonable ductility and fracture toughness, good resistance to fatigue crack initiation and low crack propagation rates [1]. One alloy commonly used as disk material in gas turbines is alloy 718 [1].

Turbine disks may have complex shapes where several geometric features act as notches (e.g. the blade attachments). Such notches act as stress raisers and influence the load at fracture as well as the fatigue life. Fatigue life predictions of turbine disks thus involve taking notch effects into account.

Predictions of failure based on the notch root stress may be overly conservative. A steep stress gradient at the notch can cause the stress to drop significantly with distance from the notch resulting in the observed fatigue life to exceed the predicted life based on the notch root stress, so called notch support $[2,3]$.

One way of reducing conservatism is through the use of critical distances [4]. Rather than basing the failure criterion on the notch root stress (or strain), the stress/strain at some distance from the notch is thought to be more representative for the severity of the load at the notch. For example, in the case of monotonic failure, the failure is assumed to occur when the stress at a critical distance, $r$, reaches a critical value, $\sigma_{0}$,

$$
\sigma(r)=\sigma_{0}
$$

where

$$
r=\frac{1}{2 \pi}\left(\frac{K_{c}}{\sigma_{0}}\right)^{2}
$$

with $K_{c}$ and $\sigma_{0}$ being (at least similar to) the fracture toughness and the ultimate tensile strength. The theory of critical distances has been shown to be applicable also for high cycle fatigue (HCF) in which case [4]

$$
r=\frac{1}{2 \pi}\left(\frac{K_{t h}}{\sigma_{0}}\right)^{2}
$$

with $K_{t h}$ being (at least similar to) the threshold stress intensity factor for crack growth; $\sigma_{0}$ may, in this case, be more suitably chosen as the fatigue limit.

Leidermark et al. [5] have successfully used critical distances for predicting crack initiation from the strain range at low cycle fatigue (LCF) of notched specimens made from a Ni-based single-crystal alloy at $500{ }^{\circ} \mathrm{C}$. This was achieved by using a critical distance that depended on the fatigue life.

The purpose of the current work is to test the applicability of critical distances to predict the total life (i.e. initiation and propagation) of low cycle fatigued notched specimens made from alloy 718 . Fatigue data for a reference case (smooth specimens) were taken from literature. The theory of critical distances was applied to experimentally determined fatigue lives for notched specimens to see if the curves could be collapsed, thus enabling the LCF life of notched specimens to be predicted from data for smooth specimens.

Fatigue data for $450{ }^{\circ} \mathrm{C}$, from notched specimens, were used for calibration of needed equations and fatigue 
data for $550{ }^{\circ} \mathrm{C}$, from notched specimens, were used for validation.
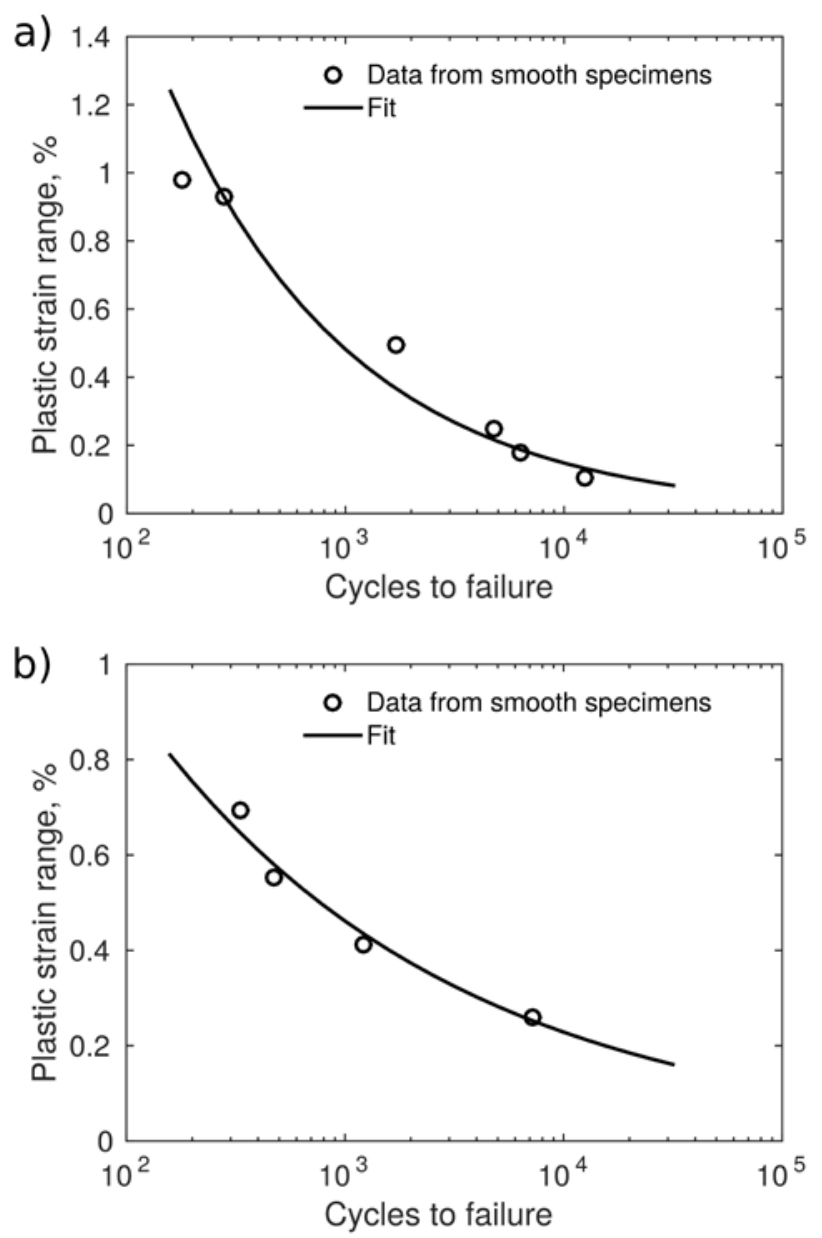

Fig. 1. Plastic strain range versus cycles to failure for smooth specimens at: a) $450{ }^{\circ} \mathrm{C}$ and b) $550{ }^{\circ} \mathrm{C}$. Experimental data from Moverare et al. [6] and curve fit according to Equation 4.

\section{Fatigue data}

\subsection{Literature data for smooth specimens}

Fatigue data (mainly in the LCF region) for smooth alloy 718 specimens are available from the work by Moverare et al. [6]. The tests were performed in strain control with $R_{\varepsilon}=0$ at $450{ }^{\circ} \mathrm{C}$ and $550{ }^{\circ} \mathrm{C}$. The fatigue lives at $450{ }^{\circ} \mathrm{C}$ and $550{ }^{\circ} \mathrm{C}$ are shown in Figure 1 versus the plastic strain range.

The data in Figure 1 lie mainly in the LCF region and is described reasonably well by a Manson-Coffin type equation [7]

$$
\frac{\Delta \varepsilon_{p}}{2}=\varepsilon_{f}^{\prime}\left(2 N_{f}\right)^{c}
$$

where $\Delta \varepsilon_{p}$ is the plastic strain range, $N_{f}$ is cycles to failure and $\varepsilon_{f}{ }^{\prime}$ and $c$ are fitting parameters given in Table 1 for $450{ }^{\circ} \mathrm{C}$ and $550{ }^{\circ} \mathrm{C}$ (based on a fit to the data by Moverare et al. [6]).
Table 1. Material data for alloy 718 for two different temperatures, $T$.

\begin{tabular}{lllccc}
\hline$T$ & $E$ & $K^{\prime}$ & $n^{\prime}$ & $\varepsilon_{f}{ }^{\prime}$ & $c$ \\
${ }^{\circ} \mathrm{C}$ & $\mathrm{GPa}$ & $\mathrm{MPa}$ & & & \\
\hline 450 & 179.0 & 1328.8 & 0.056 & 0.119 & -0.513 \\
550 & 172.3 & 2406.1 & 0.184 & 0.023 & -0.305 \\
\hline
\end{tabular}

The $\Delta \varepsilon_{p}-N_{f}$ curves shown in Figure 1 (and described by Equation 4) were used as a reference for comparison with the fatigue life of the notched specimens.

\subsection{Experiments: notched specimens}

The number of cycles to failure was established at 450 ${ }^{\circ} \mathrm{C}$ and $550{ }^{\circ} \mathrm{C}$ for notched specimens made from alloy 718. The specimen geometry was similar to that of a compact tension (CT) specimen but had a notch root radius of $2 \mathrm{~mm}$ (here referred to as a blunt notch CT specimen), see Fig. 2. The outer dimensions were 32.4 $\mathrm{mm} \times 31.2 \mathrm{~mm} \times 12 \mathrm{~mm}$.

The fatigue tests were conducted in load control with $R_{\sigma}=0.05$. Several load levels were chosen in the interval $4-10 \mathrm{kN}$. The tests were run until final rupture of the specimens.

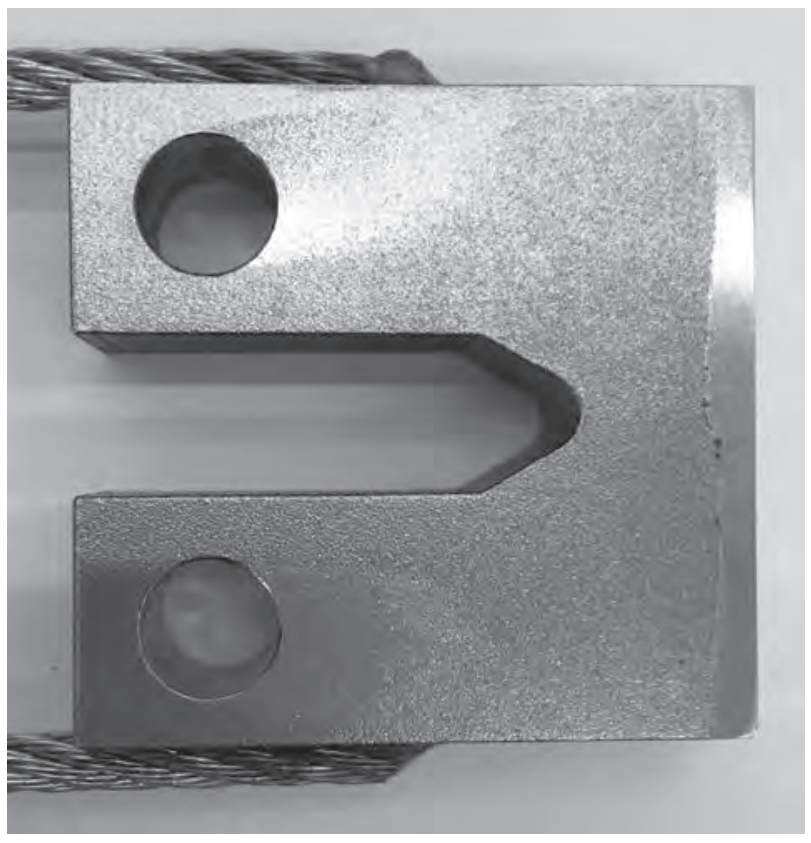

Fig. 2. The blunt notch CT specimen.

\section{An equation for the critical distance}

Equations 2 and 3 give the critical distance for the limiting cases of monotonic failure and infinite life. For crack initiation, the critical distance must vary between these extremes. It has been suggested that this can be accounted for by a cycle dependent critical distance [4, 5]

$$
r=A N_{f}^{B}
$$


where $r$ is the critical distance and $A$ and $B$ are fitting parameters. However, Equation 5 is somewhat inconvenient to use for life predictions where $N_{f}$ is unknown.

Instead, inserting Equation 4 in 5, the expression for the critical distance takes the form

$$
r=A\left(\frac{1}{2}\left(\frac{\Delta \varepsilon_{p}}{2 \varepsilon_{f}^{\prime}}\right)^{1 / c}\right)^{B}=p^{\prime} \Delta \varepsilon_{p}^{q \prime}
$$

where $p^{\prime}$ and $q^{\prime}$ are fitting parameters. Hence, the critical distance becomes a function of the plastic strain range. Furthermore, it seems intuitive that a higher load (and thus a higher strain gradient at the notch) would motivate that the life prediction is based on the state farther from the notch in order for it not to be overly conservative.

The strain range in Equation $6, \Delta \varepsilon_{p}$, should really be taken at distance $r$. Here, however, the plastic strain range at the notch root, $\Delta \varepsilon_{p}^{\text {root }}$, will be used. The

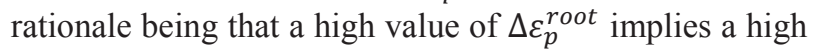
value of $\Delta \varepsilon_{p}$. Hence, it would not be too far-fetched to assume that

$$
r=p\left(\Delta \varepsilon_{p}^{r o o t}\right)^{q}
$$

where $p$ and $q$ are fitting parameters.

The number of cycles to final rupture, $N_{f}$, is the sum of the number of cycles to crack initiation, $N_{i}$ and the number of cycles of crack propagation, $N_{p}$, i.e. $N_{f}=$ $N_{i}+N_{p}$. An objection to the use of critical distances for predicting the total fatigue life might be that, after initiation, the crack will grow and extend outside the region influenced by the notch. However, it is argued here that, for low cycle fatigue, the final rupture happens at crack lengths short enough to still be located in the region where the stresses are largely determined by the notch (the average crack length at final rupture was a little over $2 \mathrm{~mm}$ with the longest crack, i.e. lowest load, being $3.5 \mathrm{~mm}$ ). Furthermore, a significant part of the total life is still made up by the crack initiation phase and, consequently, the total life is largely influenced by the stresses at the notch (the number of cycles to initiation, on average, constituted $\sim 60 \%$ of the total life in the current fatigue tests). Since the theory of critical distances could be expected to account for the notch influence on the crack initiation life for low cycle fatigue [5], it is believed that it could also be used for explaining differences in the total life.

\section{Results for notched specimens}

\subsection{Calculation of strain ranges}

The stresses in the notched specimen were calculated by a linear-elastic finite element analysis (FEA) in the commercial finite element code Abaqus. The stress around the notch scales linearly with the applied load, which enables it to be derived for all load levels from a single elastic analysis. The stress component parallel to the direction of the applied load, here referred to as the vertical component (the y-direction in Figure 3), was used for all calculations; it coincides with the maximum principal stress for this specimen geometry.

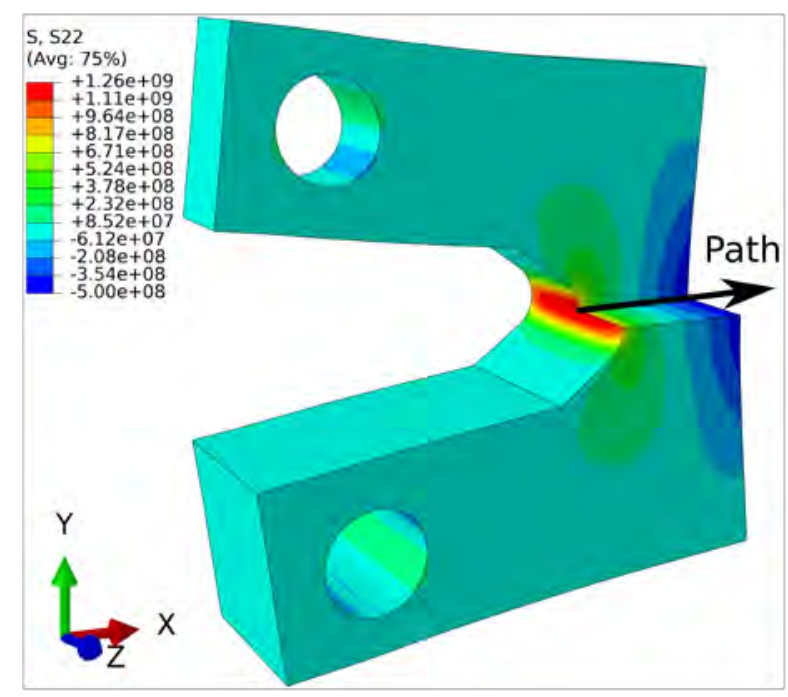

Fig. 3. A linear-elastic finite element analysis of the loaded blunt notch CT specimen. The path at which the vertical stress component (y-direction) is taken is marked by an arrow.

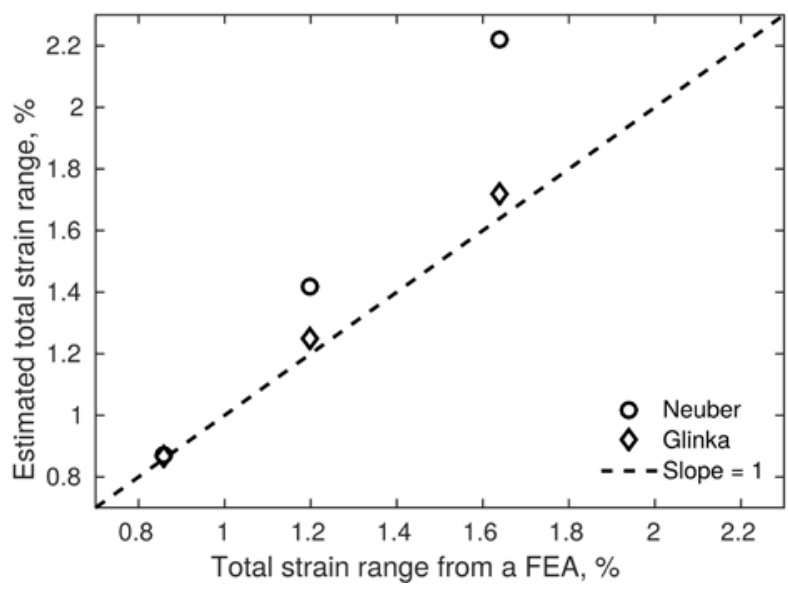

Fig. 4. Comparison of strain ranges (vertical component) at the notch root established by Neuber's rule, Glinka's rule and an elasto-plastic finite element analysis (FEA) at $450{ }^{\circ} \mathrm{C}$.

The total and plastic strain ranges can be established from the linear-elastic FEA stress using the methods of either Neuber or Glinka, together with a RambergOsgood type equation. The total strain range is obtained by solving

$$
\left\{\begin{array}{c}
\Delta \varepsilon \Delta \sigma=\frac{K_{f}^{2} \Delta \sigma_{\text {nom }}^{2}}{E} \\
\Delta \varepsilon=\frac{\Delta \sigma}{E}+2\left(\frac{\Delta \sigma}{2 K^{\prime}}\right)^{1 / n^{\prime}}
\end{array}\right.
$$

based on Neuber's rule or 


$$
\left\{\begin{array}{l}
\int_{0}^{\Delta \varepsilon} \Delta \sigma d \Delta \varepsilon=\frac{K_{f}^{2} \Delta \sigma_{\text {nom }}^{2}}{2 E} \\
\Delta \varepsilon=\frac{\Delta \sigma}{E}+2\left(\frac{\Delta \sigma}{2 K^{\prime}}\right)^{1 / n^{\prime}}
\end{array}\right.
$$

based on Glinka's rule. The fatigue notch factor is set to $K_{f}=1$ since the nominal stress, $\Delta \sigma_{\text {nom }}$, is taken locally along the path shown in Figure 3. The needed material parameters (the Young's modulus, E, and the cyclic Ramberg-Osgood parameters $K^{\prime}$ and $n^{\prime}$ ) are establish from References [6, 8, 9] and are given in Table 1. Equations 8 and 9 are solved for $\Delta \varepsilon$ and $\Delta \sigma$.

The strain ranges estimated from Equation 8 and 9 were compared to an elasto-plastic finite element analysis at a few selected load levels using an Armstrong-Frederick type material model calibrated using data from Gustafsson et al. [10, 11]. The comparison is shown in Figure 4 where it can be seen that Glinka's rule is closer to the finite element results. Therefore, Equation 9 was used to calculate the strain ranges. The reason for using Glinka's rule instead of finite element modelling for establishing the strain ranges is the considerable gain in computation time thus achieved.

Figure 5 gives an example of the stress and strain ranges as function of distance from the notch (see Figure 3) for linear-elastic results from a finite element analysis and the same data recalculated using Glinka's rule.
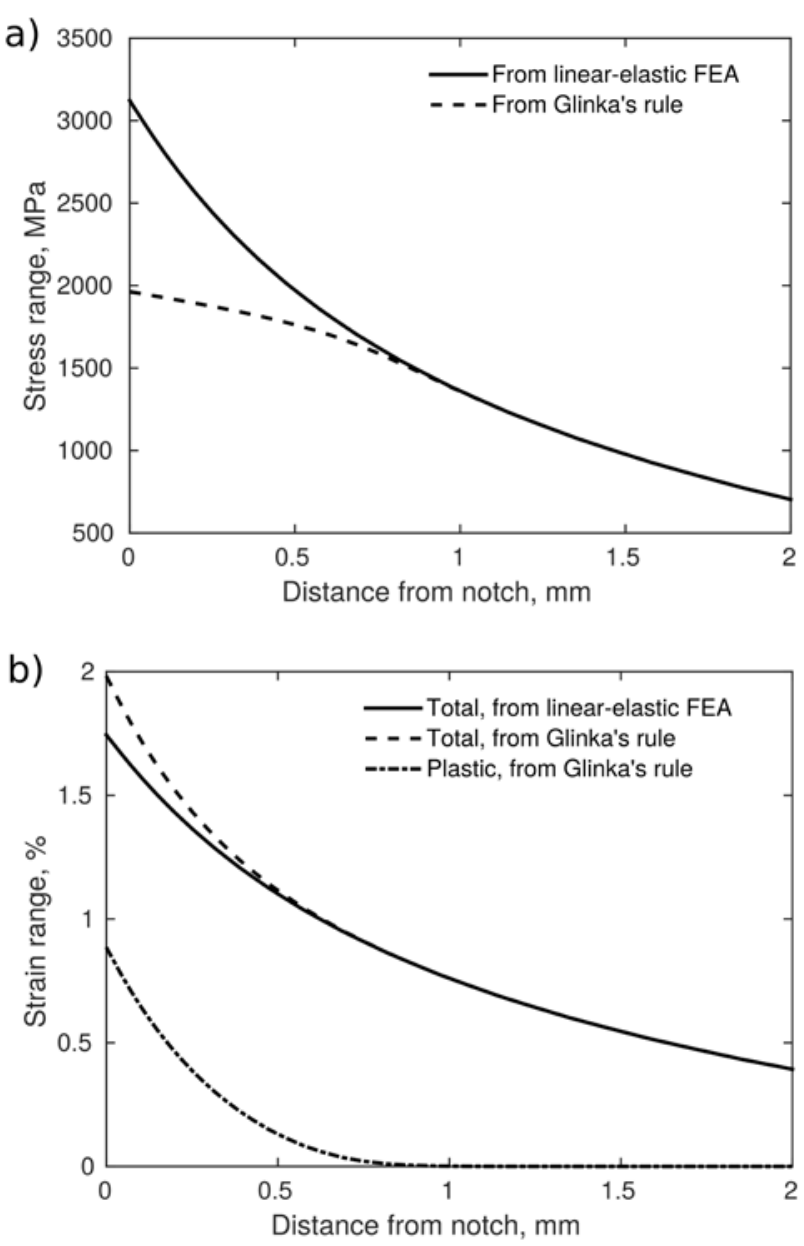

Fig. 5. Comparison of stress and strain ranges (vertical component) from a linear-elastic finite element analysis (FEA) and Glinka's rule at $450{ }^{\circ} \mathrm{C}$. a) Stress range as function of the distance from the notch at $9.9 \mathrm{kN}$ load. b) Total and plastic strain ranges as function of the distance from the notch at 9.9 $\mathrm{kN}$ load.

\subsection{Calibration of critical distance at $450^{\circ} \mathrm{C}$}

Fatigue data for smooth and notched specimens at 450 ${ }^{\circ} \mathrm{C}$ were used for calibrating the expression for the critical distance (see Equation 7).

Figure 6 shows the plastic strain range as function of number of cycles to failure; for the blunt notch CT specimens, the strain has been taken at the notch root. It can be seen that the $\Delta \varepsilon_{p}-N_{f}$ curve does not coincide with the curve for the smooth specimens from Moverare et al. [6]. The predicted life to failure based on data for smooth specimens and the notch root strain range from the notched specimens would obviously be lower than the observed life. 


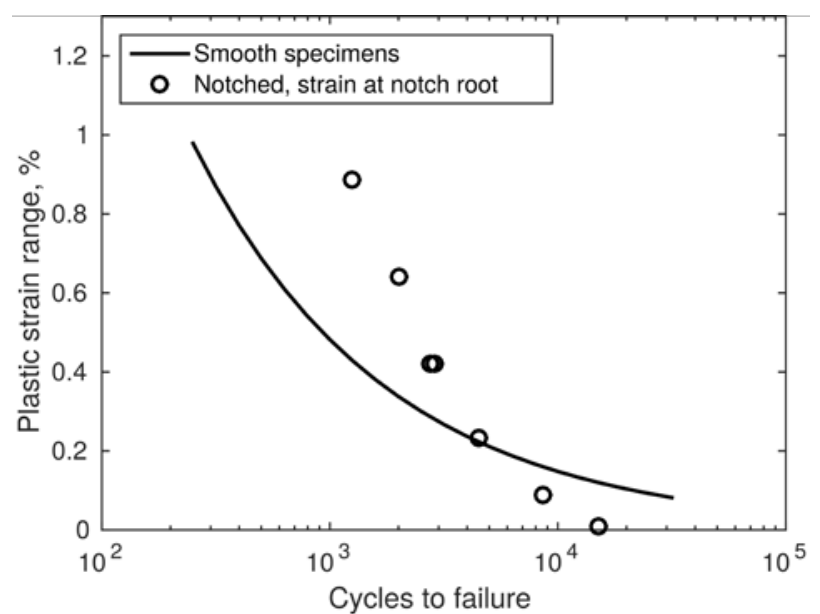

Fig. 6. Plastic strain range versus number of cycles to failure at $450{ }^{\circ} \mathrm{C}$. Comparison between data for smooth specimens (from Moverare et al. [6]) and notched specimens. For the latter, the plastic strain range has been taken at the notch root.

It should be noted, however, that the notch support seems to diminish around 5000-10000 cycles. As seen in Figure 6, this occurs as the plastic strain range becomes low and thus coincides with the transition from LCF to HCF behaviour. Consequently, notch support should only be expected in the LCF regime and, in the current work, data points with lives longer than $\sim 5000$ cycles will be ignored.

To find the fitting parameters $p$ and $q$ in Equation 7, the following procedure was used:

1. Using Equation 4 fitted to data for smooth specimens, the expected plastic strain range, $\Delta \varepsilon_{p}^{*}$, was established for each experimentally observed life for the notched specimens, $N_{f}^{\text {notch }}$, such that $\Delta \varepsilon_{p}^{*}=2 \varepsilon_{f}{ }^{\prime}\left(2 N_{f}^{\text {notch }}\right)^{c}$.

2. For each load level, the distance from the notch, $r^{*}$, corresponding to $\Delta \varepsilon_{p}^{*}$ was established from curves as that shown in Figure $5 \mathrm{~b}$ ).

3. The distances, $r^{*}$, were plotted versus the plastic strain range from the blunt notch CT specimens taken at the notch root and Equation 7 was fitted.

Figure 7 shows the obtained critical distances for data at $450{ }^{\circ} \mathrm{C}$ plotted versus the plastic strain range at the notch root from the blunt notch CT specimens; as seen, Equation 7 provides a reasonable fit to the data (albeit less accurate for lower loads). The fitting parameters in Equation 7 are $p=0.0741 \mathrm{~m}$ and $q=1.2184$.

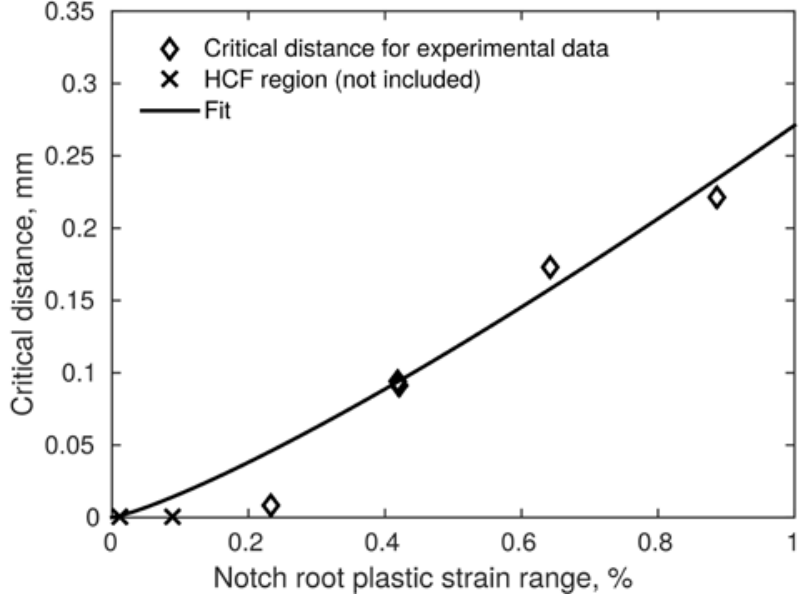

Fig. 7. The distance from the notch (the critical distance) at which the plastic strain range should be extracted from the blunt notch CT specimens in order for the fatigue life to be predicted by $\Delta \varepsilon_{p}-N_{f}$ curves for smooth specimens; plotted versus the plastic strain range at the notch root.

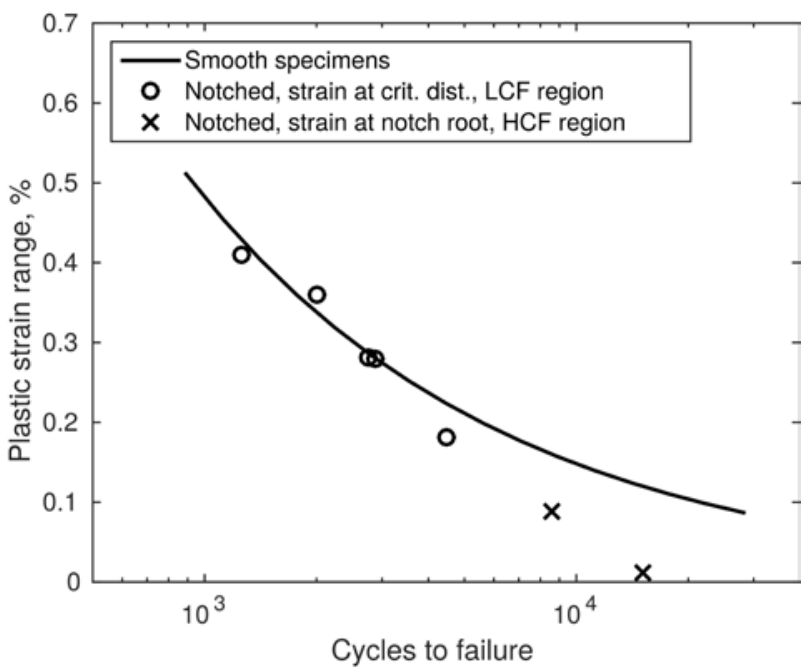

Fig. 8. Plastic strain range versus cycles to failure for smooth and notched specimens. For the notched specimens, the strain has been taken at the critical distance. Above $\sim 5000$ cycles, no notch support is expected and those data points should be ignored.

Figure 8 shows a comparison of $\Delta \varepsilon_{p}-N_{f}$ curves for smooth specimens and blunt notch $\mathrm{CT}$ specimens with the strain taken at the critical distance as determined by Equation 7. As seen, the curves collapse reasonably well. Fatigue data for smooth specimens can thus be used for the total life prediction of notched specimens if the prediction is based on the strain range taken at the distance $r$ from the notch where $r$ is given by Equation 7.

It is important to note, though, that notch support only seems to have an effect for shorter lives. Specimens that lived longer than $~ 5000$ cycles should hence be ignored here. Since the region around 5000-10000 cycles coincides with very low plastic strain ranges, it can be concluded that notch support only takes effect in the LCF region. 


\subsection{Validation at $550^{\circ} \mathrm{C}$}

To justify the chosen method for calculating the critical distance, a validation was performed for fatigue data from tests at $550{ }^{\circ} \mathrm{C}$.

Figure 9 shows the plastic strain range versus cycles to failure for fatigue at $550^{\circ} \mathrm{C}$; for the blunt notch $\mathrm{CT}$ specimens, the strain has been taken at the notch root. Just as for $450{ }^{\circ} \mathrm{C}$ (see Figure 6), the blunt notch CT specimens had longer lives than would be predicted from data from smooth specimens. Again, notch support only seems to exist for lives shorter than about 5000 cycles.

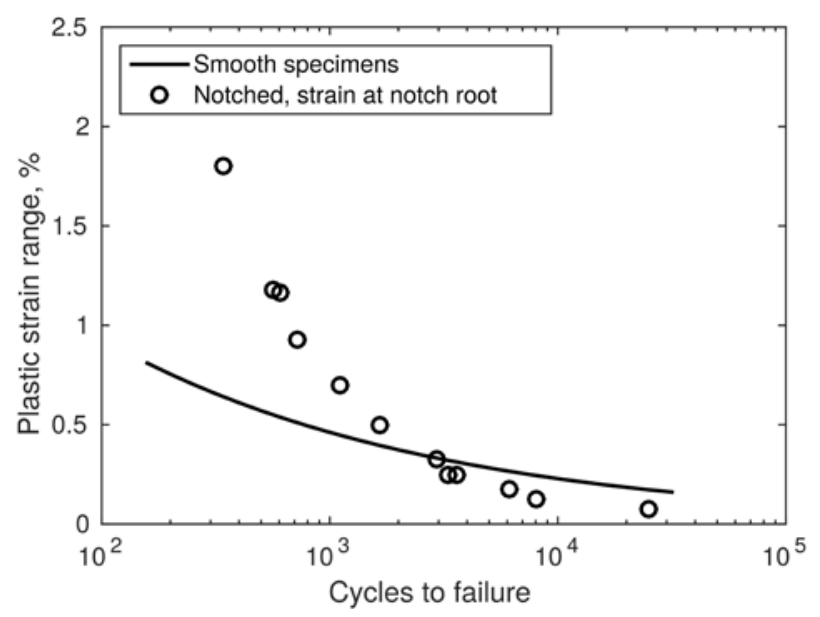

Fig. 9. Plastic strain range versus number of cycles to failure at $550{ }^{\circ} \mathrm{C}$. Comparison between data for smooth specimens (from Moverare et al. [6]) and notched specimens. For the blunt notch $\mathrm{CT}$ specimen, the plastic strain range has been taken at the notch root.

A life prediction was made for the blunt notch $\mathrm{CT}$ specimens using data for smooth specimens at $550{ }^{\circ} \mathrm{C}$ by the following procedure:

1. Stress versus distance from the notch was obtained from an elastic FE analysis for each load level.

2. Equation 9 (Glinka) was used to establish the plastic strain range versus distance from the notch.

3. The critical distance, for each load level, was calculated from the notch root plastic strain range and Equation 7 calibrated with data for $450^{\circ} \mathrm{C}$.

4. The plastic strain range, $\Delta \varepsilon_{p}^{r}$, was taken at the critical distance, $r$, for each load level.

5. The fatigue life of the notched specimens, $N_{f}^{\text {notch }}$, was predicted as $N_{f}^{\text {notch }}=$ $\frac{1}{2}\left(\frac{\Delta \varepsilon_{p}^{r}}{2 \varepsilon_{f^{\prime}}}\right)^{1 / c}$ with $\varepsilon_{f}{ }^{\prime}$ and $c$ calibrated to data for smooth specimens at $550{ }^{\circ} \mathrm{C}$.

The thus predicted life is shown in Figure 10; as seen, the use of critical distances reduces the conservative prediction (would it have been made based on the notch root strain) and thus accounts for the notch support in the LCF region.

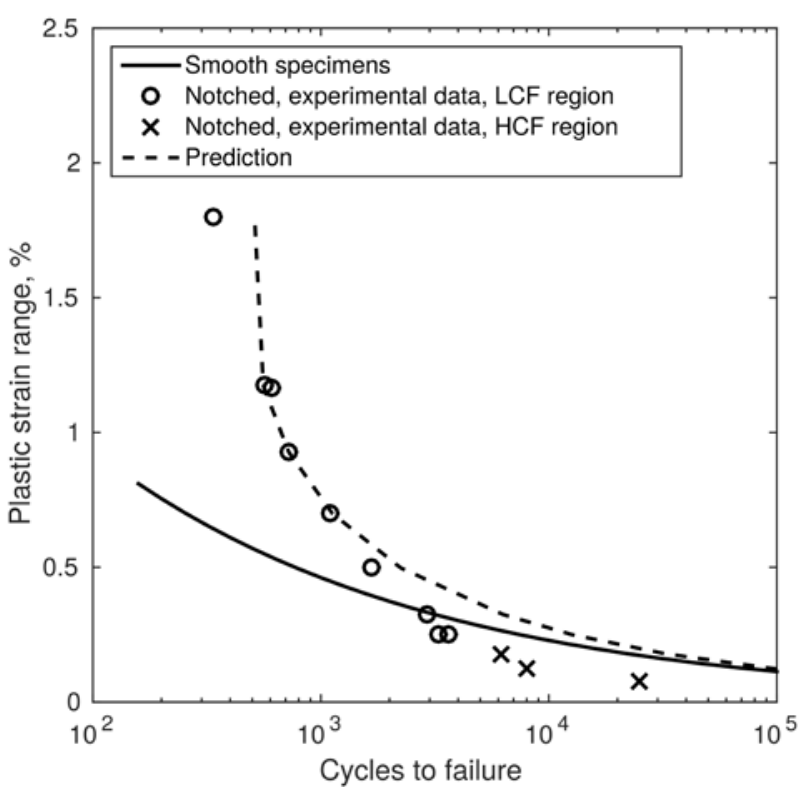

Fig. 10. Plastic strain range versus number of cycles to failure at $550{ }^{\circ} \mathrm{C}$. For the notched specimens, the prediction has been made using the plastic strain range at the critical distances and a $\Delta \varepsilon_{p}-N_{f}$ curve calibrated for smooth specimens.

\section{Conclusions}

The theory of critical distances was applied to low cycle fatigue of blunt notch CT specimens made from alloy 718 in an attempt to allow for total life prediction of notched specimens to be made from data for smooth specimens. It was argued that, in the low cycle fatigue regime, the final rupture occurs at crack lengths short enough to still be in the stress field influenced by the notch; additionally, the initiation part of the fatigue life (which is heavily influenced by the notch stress) constitutes a significant part ( $\sim 60 \%)$ of the total life. A critical distance based life prediction approach should therefore be applicable also for the total life in the low cycle regime.

It was found that the critical distance, with reasonable accuracy, could be calculated from the notch root plastic strain range via a simple power law. It was also found, however, that the notch support diminishes at around 5000-10000 cycles with the transition into the high cycle regime. The critical distance based life prediction approach should hence be applied only in the low cycle regime.

The use of critical distances collapsed the $\Delta \varepsilon_{p}-N_{f}$ curves for smooth and blunt notch CT specimens at 450 ${ }^{\circ} \mathrm{C}$ and was justified by validation at $550{ }^{\circ} \mathrm{C}$. The method of critical distances could arguably be used for accounting for the notch support in low cycle fatigue total life predictions of notched components.

This project has received funding from the European Union's Horizon 2020 research and innovation programme under grant agreement No. 653941.

\section{References}


1. R. Reed, The superalloys - fundamentals and applications (Cambride University Press, The Edinburgh Building, Cambride CB2 8RU, UK, 2008)

2. C. Kontermann, H. Almstedt, A. Scholz, M. Oechsner, Procedia Structural Integrity 2, 3125 (2016)

3. L. Mäde, H. Gottschalk, S. Schmitz, T. Beck, G. Rollmann, Probabilistic LCF Risk Evaluation of a Turbine Vane by Combined Size Effect and Notch Support Modeling, in ASME. Turbo Expo: Power for Land, Sea, and Air, Volume 7A: Structures and Dynamics (2017)

4. D. Taylor, The theory of critical distances (Elsevier, The Boulevard, Langford, Kidlington, Oxford, OX5 1GB, UK, 2007)

5. D. Leidermark, J. Moverare, K. Simonsson, S. Sjöström, Int. J. Fatigue 33, 1351 (2011)

6. J. Moverare, G. Leijon, H. Brodin, F. Palmert, Mater. Sci. Eng. A 564, 107 (2013)

7. S. Manson, G. Halford, Fatigue and Durability of Structural Materials (ASM International, 2006)

8. M. Fukuhara, A. Sanpei, J. Mater. Sci. Letters 12, 1122 (1993)

9. H. Ledbetter, Cryogenics December, 653 (1982)

10. D. Gustafsson, Ph.D. thesis, Linköpings universitet (2012)

11. D. Gustafsson, J.J. Moverare, K. Simonsson, S. Sjöström, J. Eng. Gas Turbines Power 133, 094501$1(2011)$ 